\title{
Sosialisasi Potensi Beberapa Varietas Sorgum Sebagai Bahan Baku Makanan Olahan
}

\author{
Eka Candra Lina ${ }^{1}$ dan Wenny Surya Murtius ${ }^{2}$ \\ 1Fakultas Pertanian, Universitas Andalas, Kampus Limau Manis, Padang, 25163. Indonesia \\ ${ }^{2}$ Fakultas Teknologi Pertanian, Universitas Andalas, Kampus Limau Manis, Padang, 25163. Indonesia \\ E-mail: ekacandra222@gmail.com
}

Keywords:

community

service, processed food, sorghum
Kata Kunci: makanan olahan, pengabdian masyarakat, sorgum, transfer teknologi

\begin{abstract}
Sorghum farmers in West Sumatra, especially Padang Pariaman, have low knowledge of sorghum varieties in plants. This is because sorghum relatively new food commodity cultivated in this area. The three varieties of sorghum that are often grown by farmers are numbu, Super 1, and red varieties, which differ in morphology, texture, and taste. The general procedure for harvesting sorghum begins with cutting panicles, drying them in the sun, threshing them, and drying them again until the moisture content reaches $12 \%$. Then the sorghum seeds are crushed using a sosoh machine so that the tannin in the outer skin layer is lost. After going through the filling process, sorghum rice is produced, can be consumed directly by cooking it into porridge, cooked like rice, or mixed with rice (rasgum). Sorghum rice can also be ground into flour and used as a base for making various types of food. The community service team has carried out a chemical analysis of sorghum flour. There are amylose and amylopectin analysis, starch content analysis, starch gelatinization profile, and reducing sugar. The objective of this activity is to transfer knowledge and technology related to sorghum rice and sorghum flour as raw materials for food processing. From the data obtained, known that red sorghum has the best performance as raw material for wet-processed food, while Numbu and Super 1 are suitable as raw materials for dry processed food.
\end{abstract}
ABSTRAK
Pengetahuan petani sorgum di Sumatera Barat khususnya Padang Pariaman mengenai varietas sorgum masih rendah. Hal ini disebabkan karena sorgum adalah komoditas pangan yang relatif baru dibudidayakan di daerah ini. Tiga varietas sorgum yang sering ditanam oleh petani adalah varietas numbu, Super 1, dan merah, dimana secara morfologi, tekstur, dan rasa ketiganya berbeda. Prosedur umum panen sorgum diawali dengan potong malai, dijemur, dirontokkan, dijemur kembali hingga kadar air mencapai $12 \%$. Selanjutnya biji disosoh menggunakan mesin sosoh agar tannin yang berada di lapisan kulit luar hilang. Setelah melewati proses penyosohan dihasilkan beras sorgum yang dapat dikonsumsi menjadi bubur atau dicampur dengan beras (rasgum). Beras sorgum juga bisa digiling menjadi tepung dan dijadikan bahan dasar untuk membuat berbagai jenis makanan. Tim pengabdian kepada masyarakat telah melakukan analisis kimia tepung sorgum yang meliputi analisa amilosa dan amilopektin, Analisa kadar pati, profil gelatinisasi pati, dan gula pereduksi. Tujuan kegiatan ini adalah transfer pengetahuan dan teknologi terkait beras sorgum dan tepung sorgum sebagai bahan baku olahan makanan. Dari data yang diperoleh diketahui bahwa sorgum merah memiliki performa terbaik untuk dijadikan bahan baku makanan olahan basah sedangkan Numbu dan Super 1 cocok dijadikan bahan baku makanan olahan kering. 


\section{PENDAHULUAN}

Tanaman sorgum termasuk tanaman serelia yang memiliki kandungan gizi tinggi, meliputi karbohidrat, lemak, kalsium, besi dan fosfor (Suarni dan Firmansyah, 2013). Nagari Kasang yang berada di Kecamatan Batang Anai, Kabupaten Padang Pariaman merupakan salah satu nagari yang memiliki lahan sorgum yang cukup luas. Saat ini, tercatat luas lahan sorgum di nagari Kasang ada sekitar \pm 1 ha. Produksi sorgum di nagari Kasang dalam satu kali panen $\pm 4,5$ ton/Ha. Kelompok tani di Nagari Kasang biasanya hanya mengkonsumsi sorgum untuk keperluan pribadi. Dimana sorgum yang telah panen, bijinya dikeringkan dan di rontokkan, kemudian di sosoh hingga menghasilkan beras sorgum. Proses selanjutnya adalah melalui proses penggilingan yang dapat menghilangkan kulit biji dan bagian lembaga (germ) sedangkan endosperm dihaluskan sampai pada derajat kehalusan yang sesuai dan disebut tepung. Tepung merupakan produk yang memiliki kadar air rendah sehingga daya awetnya pun tinggi (Winarno 1997; Damardjati dkk, 2000). Kriteria tepung sorgum dipengaruhi oleh warna dan varietas sorgum yang digunakan. Varietas sorgum yang berwarna lebih terang akan menghasilkan tepung yang lebih putih dan begitu pula sebaliknya. Tepung dari varietas yang berwarna gelap memiliki rasa yang lebih pahit sehingga lebih cocok sebagai bahan dasar minuman (Mudjisihono dkk, 1987).

Beras sorgum biasanya dimasak seperti memasak beras pada umumnya atau dapat juga di campur dengan beras (1:2), selain itu juga bisa diolah menjadi nasi goreng, nasi liwet dll. Tepung sorgum dapat diolah menjadi bahan baku snack ekstrusi, mi, maupun sebagai tepung substitusi pada berbagai produk seperti roti, cookies, pop sorgum, bubur, mie dan snack ekstrusi (Sirappa 2003). Pembuatan cookies menggunakan tepung sorgum masih diperlukan penambahan maizena untuk mengurangi rasa sepat dan sebagai bahan perekat (Suarni, 2004).

Kelompok Wanita Tani (KWT) Kabun Raya membudidayakan sorgum di daerah Palapa Pariaman dalam skala yang cukup luas dan berniat membuat berbagai jenis makanan olahan berbahan dasar sorgum untuk menambah pendapatan keluarga. Pengetahuan dasar mengenai tepung sorgum perlu diketahui agar dapat digunakan sesuai kebutuhan secara tepat. Tepung sorgum memiliki tekstur dan performa yang berbeda dibandingkan jenis tepung lainnya yang biasa digunakan sebagai bahan baku makanan olahan. Oleh karena itu tim pengabdian Unand melakukan sosialisasi yang diberi judul "Potensi beberapa Varietas Sorgum sebagai Bahan Baku Makanan Olahan".

\section{METODE}

\section{Waktu dan Tempat}

Kegiatan pengabdian kepada masyarakat dilaksanakan pada bulan Agustus 2020 di daerah Palapa, Padang Pariaman kepada mitra Kelompok Wanita Tani (KWT) Kabun Raya.

\section{Pelaksanaan Kegiatan}

Kegiatan Bersama mitra KWT Kabun Raya diawali dengan teknik penanaman sorgum sebagai contoh dan media pembelajaran langsung terkait budidaya sorgum yang baik dan benar. Daerah Pariaman sangat cocok untuk di tanami sorgum, kondisi geografis dataran rendah, cahaya matahari cukup dan minim air. Adanya transfer pengetahuan dan teknologi tepat guna tentang bahan baku olahan makanan berbasis sorgum akan memperlancar usaha yang dirintis oleh KWT Kabun Raya dalam rangka meningkatkan pendapatan keluarga. Dukungan terhadap usaha rintisan seperti ini sangat diperlukan agar mampu berkembang, 
stabil, mandiri dan berdampak positif terhadap perekonomian masyarakat. Binaan berupa inkubasi akan dilakukan oleh inkubator bisnis teknologi Unand seperti yang dilakukan terhadap UMKM di Nagari Sinuruik yang mampu meningkatan kualitas maupun kuantitas produk, dan mampu bersaing di pasar lokal dan regional (Lina dkk., 2019). Selain melakukan penyulahan terhadap KWT Kabun Raya, juga dilakukan penelitian terkait analisis kimia tepung sorgum yang meliputi Analisa amilosa dan amilopektin, Analisa kadar pati, profil gelatinisasi pati, dan gula pereduksi. Hal ini guna untuk menentukan varietas sorgum yang cocok diguanakan untuk pembutan produk-produk turunan dari tepung sorgum. Penelitian ini dilakukan di Laboratorium Teknologi Hasil Pertanian Universitas Andalas.

Metode sosialisasi adalah dengan demplot dan penyuluhan seperti yang di lakukan oleh (Febjislami S, 2020).

1. Penyuluhan, dilakukan untuk memberikan pemahaman kepada mitra KWT Kabun Raya tentang beberapa varietas sorgum (ciri morfologi, kandungan, dan penggunaannya), pengetahuan ini penting untuk menghindari kegagalan dalam pembuatan makanan olahan berbasis sorgum.

2. Demplot, beberapa varietas sorgum yang dikenalkan kepada mitra yaitu sorgum merah, super 1, dan Numbu ditanam di lokasi KWT Kabun Raya dengan tujuan agar kelompok sasaran bisa langsung mengamati, mempelajari, dan membandingkan ketiga jenis sorgum tersebut.

Kegiatan diawali dengan panen yang dilakukan bersama-sama dengan mitra KWT Kabun Raya, selanjutnya dilakukan penyuluhan untuk menyampaikan materi dilengkapi diskusi dan tanya jawab.

\section{HASIL DAN PEMBAHASAN}

Tiga varietas sorgum yang ditanam adalah varietas numbu, varietas merah dan varietas Super 1. Bibit tiga varietas sorgum ini berasal dari Balai Penelitian Tanaman Serealia (Balitsereal), Maros Sulawesi Selatan. Tiga jenis sorgum ini sering di tanam orang dengan beberapa kelebihan dan kekurangannya (Sumarno et al., 2013).

Tabel 1. Kriteria tiga varietas sorgum yang di tanaman oleh Kelompok Wanita Tani Kabun Raya

\begin{tabular}{lllll}
\hline No & Kriteria & Numbu & Super 1 & Merah \\
\hline 1 & Bentuk Malai & Kompak & Semi kompak & Semi terbuka \\
2 & Kelompok kultivar & Durra & Kafir & Caudatum \\
3 & Hasil Biji & Tinggi & Sedang & Sedang \\
4 & Warna biji & Kuning pudar & Abu-abu pudar & Merah \\
5 & Rasa & Manis & Biasa & Agak pahit \\
\hline
\end{tabular}



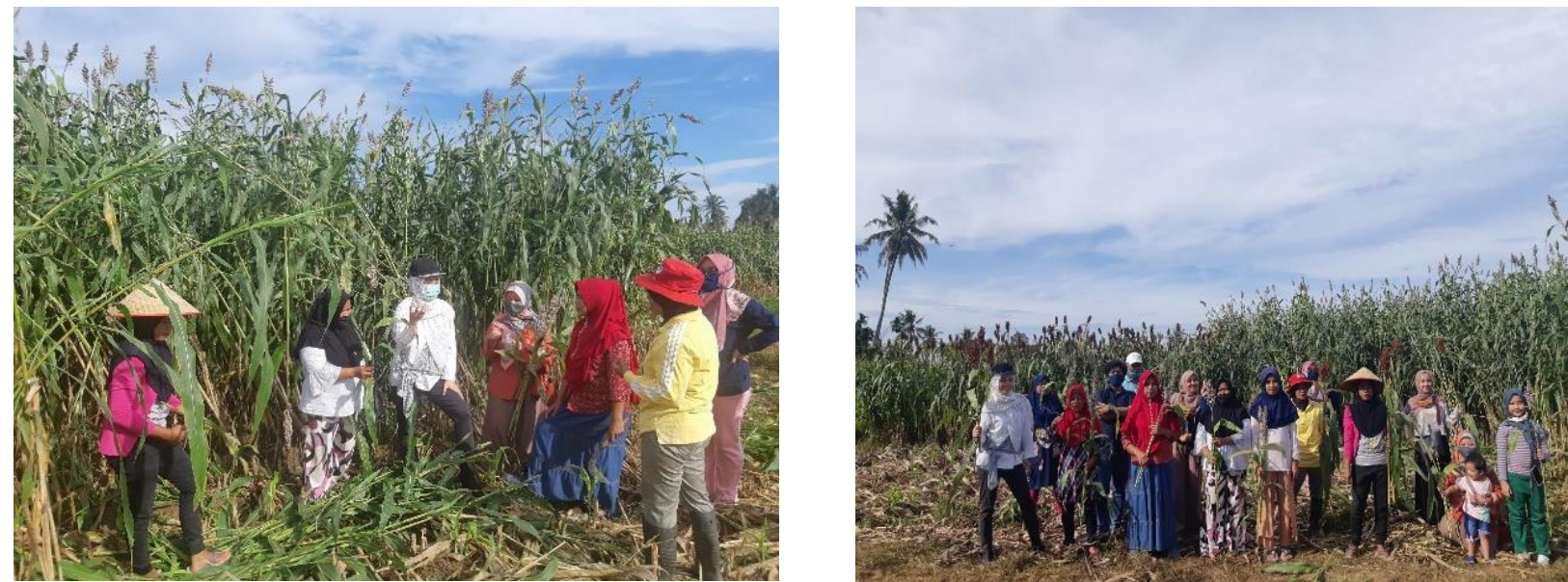

Gambar 1. Panen sorgum Bersama Kelompok Wanita Tani Kabun Raya

Beras sorgum yang telah bersih digiling menjadi tepung, kemudian digunakan sebagai bahan dasar olah pangan, berikut pengamatan terhadap kandungan amilosa, amilopektin, pati, gula pereduksi dan suhu gelatinisasi (Tabel 2).

Tabel 2. Hasil Analisa Tepung Sorgum dari Berbagai Varietas

\begin{tabular}{lccc}
\hline \multirow{2}{*}{\multicolumn{1}{c}{ Analisis }} & \multicolumn{2}{c}{ Tepung Sorgum dari Berbagai Varietas } \\
\cline { 2 - 4 } & $\begin{array}{c}\text { Numbu } \\
\text { Rata-rata } \pm \text { SD }\end{array}$ & $\begin{array}{c}\text { Merah } \\
\text { Rata-rata } \pm \text { SD }\end{array}$ & $\begin{array}{c}\text { Super } 1 \\
\text { Rata-rata } \pm \text { SD }\end{array}$ \\
\hline Amilosa (\%) & $11,021 \pm 0,672$ & $10,847 \pm 0,571$ & $10,929 \pm 0,145$ \\
Amilopektin (\%) & $88,977 \pm 0,672$ & $89,152 \pm 0,571$ & $89,07 \pm 0,145$ \\
Pati (\%) & $36,437 \pm 0,926$ & $71,359 \pm 1,209$ & $70,302 \pm 1.724$ \\
Gula Pereduksi (\%) & $2,540 \pm 0,057$ & $4,055 \pm 0,039$ & $2,62 \pm 0,088$ \\
Waktu Gelatinisasi (menit) & 44,40 & 38,54 & 85,30 \\
Suhu Gelatinisasi ( ${ }^{\circ}$ C) & 86,2 & 84,1 & 48,20 \\
Viskositas (BU) & 990 & 1241 & 1138 \\
\hline
\end{tabular}

Keterangan: $\mathrm{SD}=$ Standar Deviasi

Amilosa dan amilopektin merupakan komponen utama penyusun pati. Kandungan pati dari tiap-tiap tepung jumlahnya berbeda-beda, begitupun perbandingan amilosa dan amilopektinya. Peranan perbandingan amilosa dan amilopektin akan berpengaruh terhadap sifat reologi bahan tersebut (Suprijadi, 2012). Berdasarkan Tabel 1 diatas bahwa tepung sorgum numbu memiliki kadar amilosa tertinggi 11,021\% sekaligus memiliki kadar amilopektin terendah yaitu 88,977\%. Sedangkan sorgum merah memiliki kadar amilopektin tertinggi 89,152\% sekaligus memiliki kadar amilosa terendah 10,847\%. 


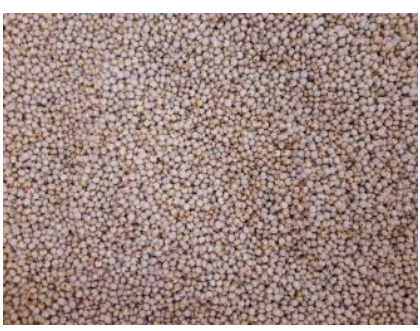

A

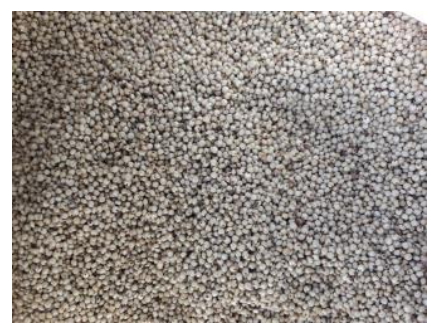

B

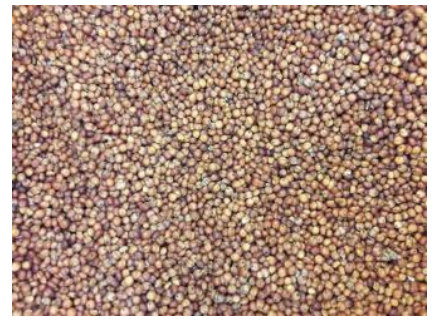

$\mathrm{C}$

Gambar 2. A. Biji sorgum Numbu, B. Biji sorgum Super 1, C. Biji Sorgum Merah

Amilosa dan amilopektin berpengaruh pada tekstur beras padi maupun non padi setelah ditanak. Menurut Yusof et al., (2005) beras yang mengandung amilosa yang tinggi akan menghasilkan nasi pera dan tekstur keras setelah dingin, sedangkan beras yang mengandung amilopektin yang tinggi akan menghasilkan nasi yang pulen dan tekstur yang lunak. Pati digunakan sebagai bahan pengental dan penstabil dalam makanan (Fortuna, 2001). Berdasarkan Tabel 1 diatas bahwa tepung sorgum merah memiliki kadar pati tertinggi 71,359\%. Sedangkan tepung sorgum numbu memiliki kadar pati terendah 36,437\%.

Tabel 2 menunjukkan kandungan gula reduksi pada varietas tepung sorgum numbu, merah dan F1 adalah sebesar 2,540\%, 4,055\% dan 2,62\%. Ketiga jenis tepung sorgum dari berbagai varietas ini kadar gula reduksi yang paling tertinggi terdapat pada tepung sorgum varietas merah, sedangkan kadar gula reduksi terendah terdapat pada tepung sorgum varietas numbu. Gula reduksi merupakan golongan gula (karbohidrat) yang mempunyai kemampuan untuk mereduksi senyawa-senyawa penerima elektron. Semua monosakarida dan disakarida (kecuali sukrosa) berperan sebagai gula pereduksi. Ada tidaknya sifat pereduksi dari suatu molekul gula ditentukan oleh ada tidaknya gugus hidroksil $(\mathrm{OH})$ bebas yang reaktif (Winarno, 2004).

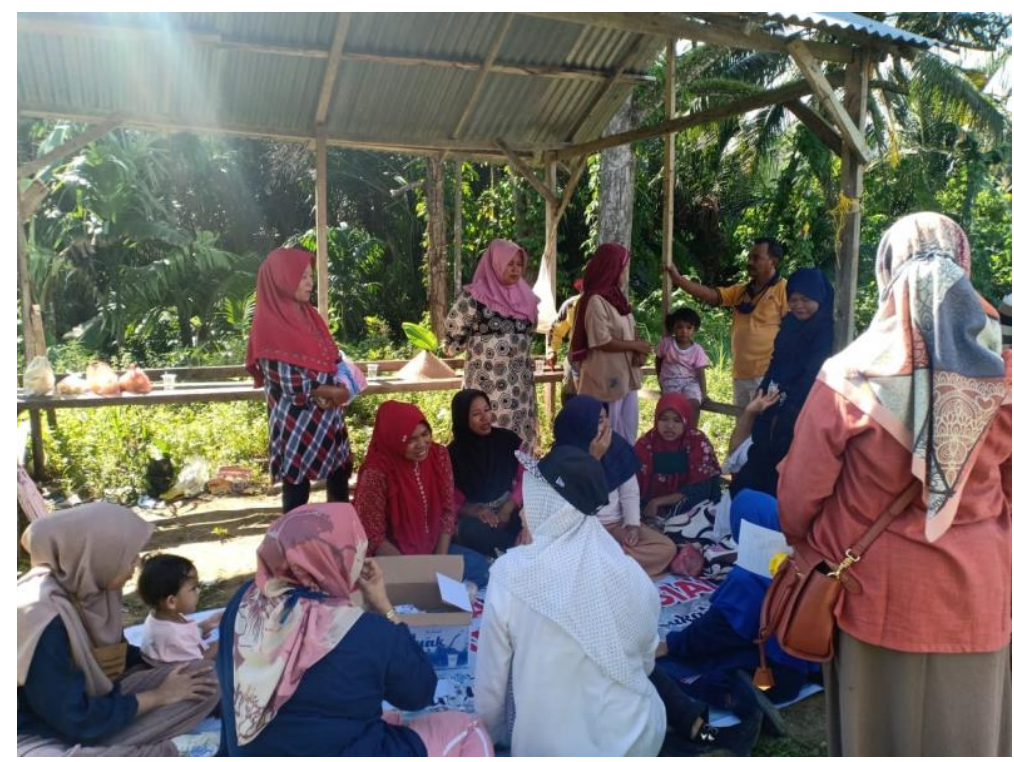

Gambar 3. Sosialisasi tentang beras dan tepung sorgum sebagai bahan dasar makanan olahan 
Selanjutnya pengujian profil gelatinisasi pati sorgum dari berbagai varietas meliputi suhu gelatinisasi, waktu gelatinisasi dan viskositas maksimum pada pati berdasarkan Tabel 2 diatas. Pati sorgum dari varietas numbu meliputi suhu gelatinisasi $86,2^{\circ} \mathrm{C}$, waktu gelatinisasi 44,40 menit dan viskositas maksimum 990 BU. Pada profil pati sorgum varietas merah didapatkan suhu gelatinisasi $84,1^{\circ} \mathrm{C}$ waktu gelatinisasi 38,54 menit dan viskositas $1241 \mathrm{BU}$. Sedangkan profil pati sorgum varietas F1 didapatkan suhu gelatinisasi $48,20^{\circ} \mathrm{C}$, waktu gelatinisasi 85,30 menit dan viskositas $1138 \mathrm{BU}$.

Kendala yang dihadapi saat ini adalah, minimnya pengetahuan KWT terhadap sorgum, sehingga sangat diperlukan upaya penyuluhan dan pelatihan terkait pengolahan sorgum menjadi produk olahan turunan. Karena, umunya KWT Kabun Raya dan penduduk sekitar hanya menggunakan sorgum untuk diolah menjadi nasi. Padahal, sorgum dapat digunakan dalam pembuatan produk-produk olahan lainnya karena dapat dijadikan sebagai pengganti tepung.

Pengetahuan terkait kandungan yang terdapat dalam tepung sorgum dapat dijadikan informasi dasar bagi KWT Kabun Raya dalam pengembangan bisnis olahan makanan berbasis sorgum. Kesesuaian jenis bahan baku akan menentukan hasil akhir produk. Misalnya tepung Numbu akan lebih cocok digunakan sebagai bahan dasar sagun sorgum, sedangkan untuk brownies lebih cocok menggunakan tepung sorgum merah.

Setelah memperoleh informasi dasar terkait kandungan sorgum, selanjutnya dilakukan penyuluhan dan pelatihan terhadap KWT Kebun Raya tentang pengolahan tepung sorgum menjadi produk-produk olahan turnan lainnya yang dapat dijadikan sebagai peluang usaha berkelanjutan untuk kedapannya. Dilakukan pelatihan-pelatihan tentang pembuatan produkproduk olahan sorgum dan bahan-bahan serta perbandingan bahan yang digunakan dalam pembuatan produk olahan sorgum.

\section{KESIMPULAN}

Secara keseluruhan dapat disimpulkan bahwa tanaman sorgum varietas Numbu, Super 1, dan Merah dapat tumbuh dengan baik di daerah Padang Pariaman. Beras sorgum dan tepung sorgum dapat dijadikan bahan dasar makanan olahan. Berdasarkan kandungan amilopektin, kandungan pati, dan profil gelatinisasi varietas sorgum numbu dan super 1 lebih cocok digunakan untuk makanan olahan kering, sedangkan varietas merah cocok digunakan untuk olahan makanan basah. Penyuluhan dan pelatihan diberikan kepada KWT Kabun Raya guna untuk dapat memberikan pelatihan terkait pembuatan produk olahan sorgum berkelanjutan sebagai salah satu usah yang dapat meningkatkan perekonomian KWT Kabun Raya.

\section{UCAPAN TERIMA KASIH}

Penulis mengucapkan terima kasih kepada LPPM Universitas Andalas dan Kerjasama dengan BPPT Sukarami. Ucapan terima kasih juga disampaikan kepada mitra yaitu Kelompok Wanita Tani (KWT) Kabun Raya dan staf Science Techno Park Unand yang berpartisipasi dalam kegiatan ini. 


\section{DAFTAR PUSTAKA}

AACC. 1983. American Association of Cereal Chemist Approved Methods. St. Paul. Minnesota. USA. Hal 154.

Apriyantono, D. FA. 1989. Petunjuk Laboratorium Analisis Pangan. Departemen Pendidikan Dan Kebudayaan Direktorat Jenderal Pendidikan Tinggi Pusat Antar Universitas Pangan Dan Gizi IPB. Bogor.

Codex Alimentarius Commission. 1995. Codex Standard for Sorghum Flour. Codex Stan 1731989 (Rev.1 1995).

Damardjati DS, Widowati S, Wargiono J, dan Pusba S. 2000. Potensi dan Pendayagunaan Sumber Bahan Lokal Serealia, Umbia-umbian, dan Kacang-kacangan untuk Penganekaragaman Pangan. Pusat Penelitian dan Pengembangan Pangan.

Febjislami S, Hayati D, Sutoyo, Santoso PJ. 2020. Teknologi Sambung Mini Untuk Mendapatkan Bibit Tanaman Durian Unggul Bagi Masyarakat Pekebun Durian Di Batu Busuk. Jurnal Hilirisasi IPTEKS, 3(2): 110-120.

Fortuna, T., L. Juszczak dan M. Palasinski. 2001. Properties of corn and wheat starch phosphates obtained from granules seg regated according to their size.EJPAU, Vol: 4.

Lina EC, Games D, Fithri P, Leony Y. 2019. Inkubasi Produk Unggulan Nagari Sinuruik Kecamatan Talamau, Kabupaten Pasaman Barat. Jurnal Nagari Membangun, 2 (3b): 288295.

Mudjisihono dan Suprapto. 1987. Budidaya dan Pengolahan Sorgum. Penebar Swadaya, Jakarta.

Sirappa MP. 2003. Prospek Pengembangan Sorgum di Indonesia sebagai Komoditas Alternatif untuk Pangan, Pakan, dan Industri. Jurnal Litbang Pertanian. Balai Pengkajian Teknologi Pertanian Sulawesi Selatan, Makassar.

Suarni. 2004. Evaluasi Sifat Fisik dan Kandungan Kimia Biji Sorgum Setelah Penyosohan. Jurnal Stigma XII (1):88-91.

Sumarno, Darmardjati DS, Syam M, Hermanto. 2013. Sorgum: Inovasi Teknologi dan Pengembangan. Badan Penelitian dan Pengembangan Pertanian. IAARD Press. Jakarta. 280 hal.

Sudarmadji, S. 2007. Analisa Bahan Makanan dan Pertanian. Liberty. Yogyakarta.

Winarno, F. G. 1997. Kimia Pangan dan Gizi. Gramedia Pustaka Utama. Jakarta.

Winarno, F. G. 2004. Kimia Pangan dan Gizi. Edisi Sebelas. Gramedia Pustaka Utama. Jakarta. 
Yusuf S.,et al., 2005. Obesity And The Risk Of Myocardial Infarction In 27000 Participants From 52 Countries: A Case Control Studies. The Lancet : 366: 1640-9. 